\title{
Miguel Ángel Gutiérrez López (2016), Itinerario de la autonomía en la Universidad Michoacana, Universidad Michoacana de San Nicolás de Hidalgo, Morelia
}

\author{
Verónica Oikión Solano \\ El Colegio de Michoacán \\ voikion@colmich.edu.mx \\ voikions@gmail.com
}

El libro en cuestión es una edición sobria realizada por la Facultad de Historia — de cuya planta académica el autor es profesor investigador-, en colaboración con la Coordinación de la Investigación Científica, ambas instancias de la Universidad Michoacana de San Nicolás de Hidalgo (UMSNH).

Gutiérrez López ha logrado, con una excelente argumentación, complejizar el fenómeno de la autonomía. Para ello el autor ha estudiado concienzudamente esta problemática desde tiempo atrás. Baste recordar otras dos obras cimeras producto de su talante investigativo: En los límites de la autonomía. La reforma socialista en la Universidad Michoacana, 1934-1943, publicada por El Colegio de Michoacán en 2011, y Autonomía y procesos políticos en la Universidad Michoacana, 1917-1963, editada por dicha universidad en 2010.

Este trabajo ha decantado un cúmulo de erudiciones: por un lado, un conocimiento profundo del devenir histórico de la Universidad Michoacana de San Nicolás de Hidalgo, desde su atropellada fundación en 1917, hasta el último tramo del siglo xx en los años ochenta; por el otro, es fruto de una minuciosa reflexión de cómo se construyó el proceso o, mejor dicho, los procesos autonómicos dentro de esa universidad, relacionados directamente con su estructura orgánica y de gobierno, así como con las interacciones de su comunidad, además de sus interrelaciones con el régimen federal y los gobiernos estatales. Estas relaciones no siempre fueron tersas, sino más bien estuvieron caracterizadas por una serie de altibajos que ilustran la complejidad de la relación Estado-universidad.

El título del libro es muy pertinente, ya que su autor ha ido desbrozando con su análisis el "itinerario", es decir, la ruta de cómo se edificaron todos los componentes de la autonomía universitaria.

En una presentación formal del libro haría unos brevísimos comentarios sobre el título de la obra, que podría haberse enmarcado en un ámbito cronológico que auxiliara al público 
lector a ubicar su temporalidad, es decir, ¿la obra pudo haber incluido en su título el lapso de 1917 a 1986? Aunque entiendo que la problemática autonómica de la UMSNH trasciende esos límites temporales, incluso hoy, a la luz del centenario nicolaita, resulta un asunto crucial y central, puesto a prueba y a debate en el difícil contexto social, político y laboral dentro del cual está inmersa esta institución en los últimos tiempos.

El libro de Gutiérrez López está conformado por una introducción, ocho capítulos, fuentes y siglario. Si bien su estructura se basa en un orden cronológico, el capitulado se centra en la problemática de la autonomía como el eje y el objetivo central para desplegar, con gran erudición argumental, todas las aristas de su constitución y morfología y, por ende, también su impacto en el quehacer universitario en sus estructuras formales y de integración orgánica.

Al final del trabajo encontramos sus fuentes, que huelga decir que no sólo se componen de obras bibliográficas, sino que incluyen un corpus documental exhaustivo, rastreado en distintos repositorios estatales, municipales y privados, así como en el Archivo General de la Nación (ACN). También el autor llevó a cabo una revisión hemerográfica pertinente; además ubicó decretos, informes, leyes y proyectos referidos primordialmente a la estructura y gobierno universitarios. En conjunto, todo ello brinda mayor valía a esta investigación, porque el manejo de ese volumen de información se hizo con una lupa analítica, demostrando el rigor y oficio de Miguel Ángel Gutiérrez López como historiador.

En cuanto al octavo capítulo, denominado "Itinerario de la autonomía universitaria en Michoacán", me parece que su contenido, que concentra el resultado de la investigación, retoma los puntos centrales de la discusión sobre la autonomía. Por tal razón, dicho capítulo debió convertirse en las "Conclusiones" o "Consideraciones finales", que por cierto no tiene esta obra. Las apreciaciones conclusivas colocadas en dicho capítulo se engarzan a un escenario lacerante vivido por la propia UMSNH en la época actual; por lo tanto, entiendo por qué el autor ha dejado abierta la puerta del pasado para entender el presente universitario y atisbar nuevas rutas que renueven y anclen el quehacer nicolaita con una visión democrática, inclusiva e integradora.

Mucha tinta ha corrido en torno a la UMSNH, sobre todo en lo que concierne a su historia y presencia fundamental como la Casa Máxima de Estudios del estado de Michoacán. Sus proyectos académicos y docentes de la educación media superior y superior representan una riqueza patrimonial, cultural y educativa para el pueblo michoacano.

Si bien distintos especialistas han fijado su atención en la autonomía universitaria, hasta ahora aún había un hueco historiográfico que proporcionara una visión de conjunto y de largo aliento —abarcador de casi todo el siglo Xx — para comprender el sentido más profundo de cómo se tejieron en distintas coyunturas históricas los diversos atributos endosados a la autonomía universitaria. 
Por tanto, Gutiérrez López nos ilustra sobre el principio de la autonomía universitaria como un fenómeno conceptual polisémico y evanescente, que puede reconstituirse, transformarse o incluso deslizarse y entrelazarse, en determinadas coyunturas, a elementos no sólo educativos, sino primordialmente históricos y hasta de carácter jurídico, político, ideológico y social. El autor señala puntualmente que su objetivo al abordar la autonomía ha sido "ofrecer, desde una perspectiva histórica, una explicación crítica de su devenir" (p. 9), en el marco de los procesos de reforma universitaria.

Y agrega que, efectivamente, el estudio de la autonomía pone "al descubierto la dificultad de establecer una definición única del fenómeno" (p. 11). De tal manera que Gutiérrez López asume la autonomía como "el resultado de un proceso (constante) de construcción y consolidación de las instituciones universitarias, afectado por las relaciones entre éstas y los poderes públicos y de diferentes sectores sociales" (p. 11).

Por ende, al formular su concepto de autonomía, la devela como "una noción móvil" (p. 11), dándole un carácter dinámico y versátil, que resulta ser una aportación muy original (como un ingrediente importante y de gran relieve para la historia conceptual), porque instrumentaliza dicha noción para evaluar las oscilaciones en la interacción — no exenta de conflictividadentre la universidad y el Estado, y, por supuesto, plasmada en distintos momentos en la cambiante y turbulenta dinámica interna universitaria. Además, mediante esta conceptualización capta con precisión la trascendencia de la contribución de la comunidad universitaria —en distintas coyunturas históricas - dentro del régimen interno de esa entidad universitaria.

Metodológicamente, Gutiérrez ha utilizado muy acertadamente las leyes orgánicas de la UMSNH (de 1919, 1921, 1933, 1939, 1961, 1966 y 1986) como la secuencia conductora, o lo que denominaríamos como "puntos coyunturales de las crestas sociales de arranque" y a la vez de arribo para explicar la autonomía como un campo de tensión en distintos planos, tanto dentro de la institución educativa (con numerosos intereses políticos e ideológicos de distintos sectores, que no suelen meramente educativos) y fuera, en el terreno de las fuerzas y grupos de presión estatales y federales, así como en la imposición de criterios y políticas públicas educativas carentes de visión o consenso social.

Al avanzar en la lectura de este trabajo, encontramos a dirigentes políticos de gran envergadura a nivel estatal, como el mismo Pascual Ortiz Rubio, en su empeño primigenio por dotar a Michoacán de una institución de educación superior con márgenes autonómicos; al gobernador Francisco J. Múgica y su muy peculiar visión de universidad como órgano del Estado, así como, en primer término, al presidente Lázaro Cárdenas - recuérdese siempre su carácter de hombre fuerte de Michoacán-, además de otras autoridades estatales y federales que, en conjunto, definen y redefinen, con el paso del tiempo, los que el autor denomina como "límites de la autonomía". 
Por supuesto que en este gran escenario político y social interactúan y dialogan, pero también se enfrentan y conflictúan, los actores políticos de primera línea con las dirigencias y las bases universitarias, quienes por momentos logran beneficios claros para la comunidad. Véase el periodo de esplendor, entre los años veinte y treinta, con un proyecto de universidad entregada a la clase trabajadora, a cargo de los rectores Jesús Díaz Barriga y Enrique Arreguín Vélez, y su relación personal con Lázaro Cárdenas y la empatía con las corrientes cardenistas; así como la reforma socialista de la Ley Orgánica impulsada por Natalio Vázquez Pallares en 1939.

En tanto que en otras situaciones extremas los nicolaitas pasan verdaderas pruebas históricas ante la cerrazón y la represión —recuérdense los movimientos universitarios de 1963 y 1966, ligados, por supuesto, a las intenciones del poder político de limitar drásticamente la autonomía-, sobre todo en los años sesenta, cuando se conjuntó una atmósfera anticomunista — producto y legado de la Guerra Fría - que empató el anticomunismo del gobernador Agustín Arriaga Rivera y el del presidente Gustavo Díaz Ordaz para mandar ejecutar con saña acciones que desmantelaron prácticamente a la universidad nicolaita.

La lectura innovadora que propone este libro sobre la autonomía y la reforma universitarias da un giro hermeneútico al revelar la historia de la UMSNH desde ángulos no trillados. Esta mirada fina del autor conduce a sus lectores para revisar nada menos que setenta años de evolución en los órdenes de la autonomía universitaria, no definidos per se, sino como torbellinos que arrojan en los espacios universitarios cambios imperativos, crisis anunciadas (como la de 1933 y la de 1943, ligadas al ideal autonómico de libre cátedra y con márgenes de autodeterminación universitaria, principalmente impulsados por Victoriano Anguiano, a semejanza del ideal autonomista de la Universidad Nacional en 1929).

Además de continuidades obligadas y fuertes rupturas, como dio cuenta el conflicto universitario de 1986, todo en el marco de zigzagueos, involuciones y retrocesos (que en términos educativos, sociales y políticos han impactado a la institución universitaria a lo largo de todo un siglo). Pero también se deben reconocer los alcances y logros trascendentes que siguen arropando e insuflando el imaginario nicolaita, no exento, desde luego, de valores como la resistencia y la lucha por las mejores causas sociales.

Al final de su libro, Gutiérrez López nos hace partícipes de una prospectiva de lo que serían los pilares renovadores de la autonomía, a la luz de la impronta, los desafíos y las redefiniciones que le esperan a la Universidad Michoacana en pleno siglo XXI, para contrarrestar el ejercicio autoritario de las funciones de sus cuerpos dirigentes y órganos universitarios.

En el último párrafo de este libro, Miguel Ángel Gutiérrez plantea, con gran visión y sensibilidad social, que el ingrediente de la democracia resulta condición sine qua non para fortalecer y ejercer una autonomía responsable y plena por parte de la Universidad Michoacana de San Nicolás de Hidalgo. Siendo una institución pública, uno de sus grandes desafíos es reivindicar 
significativamente un modelo de universidad acorde con los valores identitarios incluyentes del todo social. De ahí que, con un profundo sentido de democracia social, codo con codo con el pueblo, al que define como su razón de ser para el impulso y la transformación social. 